\title{
Traffic safety and step-by-step driving licence for young people
}

\author{
Charlotte Tonning $^{a}$, Niels Agerholm ${ }^{a}$ \\ ${ }^{a}$ Department of Civil Engineering \\ Aalborg University \\ Thomas Manns Vej 23 \\ 9220 Aalborg Ø, Denmark
}

ABSTRACT: Young novice car drivers are much more accident-prone than other drivers - up to 10 times that of their parents' generation. A central solution to improve the traffic safety for this group is implementation of a step-by-step driving licence. A number of countries have introduced a step-by-step driving licence for young drivers within the last decades. The Danish Government has also decided to introduce it for a three-year trial. The Danish trial added an opportunity to the traditional driving licence education to drive together with an experienced driver from 17 to 18 years old. This paper presents a review of safety effects from step-by-step driving licence schemes. Most of the investigated schemes consist of a step-by-step driving licence with Step 1) various tests and education, Step 2) a period where driving is only allowed together with an experienced driver and Step 3) driving without companion is allowed but with various restrictions and, in some cases, additional driving education and tests. In general, a step-by-step driving licence improves traffic safety even though the young people are permitted to drive a car earlier on. The effects from driving with an experienced driver vary with effects of up to $40 \%$ reduced accident risk, but there is a markedly reduced effect, the older the novice drivers are when they initiate the driving education. In some cases, step 3 is found to reduce accident risk with up to 61\%. As the Danish trial includes an additional step 2, and only drivers from 17 to 18 years old and with the overall significantly positive safety development in the last years, it is reasonable to assume that we can reach a safety effect of 10 to $15 \%$ among the young novice drivers from the introduction of the Danish step-bystep driving licence.

KEYWORDS: Traffic Safety; Step-by-step driving licence; Novice drivers; Driving education

\section{INTRODUCTION}

Young novice car drivers are considerably more accident-prone than more experienced road users (Færdselssikkerhedskommissionen 2013; Møller 2000, Møller 2004). The youngest drivers are up to 10 times more accident-prone than that of their parents' generation, but the risk subsides as they become older (Brems \& Munch, 2008). For example, in Denmark, every third driver of a motorized vehicle involved in an accident is between 18 and 24 years old despite the fact that young people only make up for $10 \%$ of the population (Møller, 2000). Similarly, in the United States, the fatal crash rate per distance driven for 16-19-year-olds is nearly 3 times the rate for drivers ages 20 and over. The younger, the higher risk - the fatal crash rate per distance driven is nearly double for 16-17-year-olds as it is for 18-19-year-olds (Insurance Institute for Highway Safety 2015). This pattern is suggested as general for at least the industrial part of the world.

Several reasons can be identified for this pattern. Young people are less risk averse in traffic and have a hard time reading the traffic situation (Møller, 2000, Harms et al. 2008). Also, there are individual and social factors that influence the driving behaviour such as age, gender, group norms and life style. The car is used for other purposes than for covering transportation needs. Young people use the car for e.g. visibility, status and control which all relate to either drawing attention or risky driving (Møller, 2004, Rådet for Sikker Trafik, 2015b). Records show that the risk subsides with the experience of being a driver (Høye et al. 2012).

Despite an ongoing improved traffic safety level in Denmark in recent years (Statistics Denmark 2016), 
there was a political desire for a renewed driving license education. This was partly in order to deal with the accident risk for inexperienced drivers, but also in order to liberalise the access to be a driver, in general.

The driving licence programme for a car in Denmark normally takes place at a driving school providing theoretical and practical education, night-time driving, practice on closed-off driving area and test track. As the young drivers' striking overrepresentation in the accident statistics, it was up for debate whether or not the then driving licence programme gave the young people enough experience before they received their full driving licence. The licence would be attainable at the 18th birthday at the earliest. The Danish Traffic Safety Commission also found that a modernisation of the driving licence programme was necessary (Færdselssikkerhedskommissionen, 2013). This could be done with a step-by-step driving licence. However, gathering experiences and effects from such a licence in other countries was necessary in order to ensure a documented basis for decision on potentially implementing a step-by-step driving licence in Denmark (Rigspolitiet, 2014, Rådet for Sikker Trafik, 2015a, Sølund, 2014). As elaborated on below, the experiences from step-by-step driving licence introduction in other countries were generally positive, and the current Danish government (run by the Liberals) proposed the introduction of a three-year trial with a step-by-step driving licence to cars for 17-year-olds, based on the German model for step-by-step driving licence. The proposal was adopted and the first 17-year-old drivers could drive under revised conditions from January 2017 (Regeringen, 2017).

The remaining part of this paper consists of the research questions and methodological considerations, a review of the North- and Central European results, a review of the results from the overseas countries, an exposition of the approved Danish three-year trial and finally a summary including a brief discussion of which safety effects to be expected in Denmark after implementation.

\section{RESEARCH QUESTIONS AND METHODS}

A step-by-step driving licence programme entails a driving licence in steps. The number of steps in the programme differs in the individual countries/ regions. These steps could be private driving practice with an experienced companion or solo driving with limitations and conditions. The definition of an experienced companying driver differs from country to country. The purpose of the step-by-step driving licence is to reduce driving under risky conditions as well as giving the novice drivers driving experience before they acquire a valid driving licence and can drive without special restrictions.

Based on the above-mentioned background, a literature study was managed in order to answer the following two questions:

- Which initiatives have been used in connection with step-by-step driving licences in the investigated countries?

- Which traffic safety-related effect of step-by-step driving licence implementation can be identified?

The literature review included papers and reports in English, Danish and Scandinavian languages. The search has been conducted by using the search phrases "graduated driver license (or licence)" combined with "evaluation" or "experience", and "driver" has been substituted by "driving". The search was initiated in Aalborg University's searching machine Primo, aiming at engineering databases and followed by searches in ScienceDirect, Google Scholar and Taylor Francis Online. Also, the Danish article databases from Trafikdage and from Trafik \& Veje have been searched using the English search phrases and their Danish translations.

In addition, references of relevance found in the literature review, cf. above, have been accessed to the extent of the access to these.

Based on the found literature, this paper presents information on the contents of the steps and differences and similarities of any reported safety effects. The found results are deemed too varied and within too dissimilar frames to permit any further analyses on these.

It has to be mentioned that an earlier version of these collected experiences was used as input to the consultative procedures during the development of the Danish legislative concerning the step-by-step driving licence trial.

\section{EUROPEAN EXPERIENCES WITH STEP-BY- STEP DRIVING LICENCES}

The step-by-step driving licences implemented in a number of countries are constructed after the same 
basic principle but with various age limitations, number of steps, restrictions and so on.

In Sweden until 1993, a two-step driving licence was provided: at 17.5 years old driving was allowed in the company of an experienced driver. This age was reduced to 16 years old. The age for having a full driving licence was kept at 18 years old. The experienced driver should be at least 25 years old and have had a driving license for a minimum of 5 years without suspensions. The purpose was to increase the length of time while the novice driver gained driving experience under supervision (Gregersen et al. 2000). A literature review by Gregersen et al. (2000) showed general positive effects from step-by-step driving licences including an experienced driver for supervision. Gregersen et al. reported a with-without study with comparison groups and, for the drivers not older than 20 , they found a $40 \%$ reduction in accident risk for the young people starting as 16-year-olds and $24 \%$ for those starting at 17.5 years old. The Swedish model gave an overall reduction of $15 \%$ in the accident risk for novice drivers (Gregersen et al. 2000).

In Lower Saxony, Germany, step-by-step driving licence was implemented in 2004 where after the other German federal states implemented the same model until 2008. It made it possible to start driving lessons with a driving instructor when a person is $16 \frac{1}{2}$ years old. Then a temporary driving licence could be obtained at 17 years old requiring an experienced driver of at least 30 years old and with at least 5 years of driving experience to accompany the driver until his or her $18^{\text {th }}$ year. It is recommended that the young person drives 3-5,000 km with a companion, and both parties are encouraged to participate in an introductory seminar. The novice driver can acquire a valid driving licence at 18 years old. Data from 11 of the 16 federal states of Germany were included in an effect study based on a survey with approximately 19,000 respondents. It found that, compared to young people having a traditional driving licence at 18 years old, drivers who took a step-by-step driving licence were $19 \%$ less likely to be implicated in accidents and have 22\% fewer traffic offences (Schade \& Heinzmann, 2013).

In France, the young drivers can start their step-by-step driving licence at 16 years old. The first step is theoretical and practical training for at least 20 hours at a driving school. Then they must pass a theoretical test, and the driving instructor must declare that person has sufficient driving skills before private driving practice can be initiated. The young person must drive at least 3,000 $\mathrm{km}$ during private driving practice with an experienced driver of at least 28 years old. The young person must also have two feedback meetings of three hours' duration with a driving instructor. The French model has not had a visibly documented effect (Sølund, 2014) while Fafet (in Gregersen et al. 2000) found a 70\% accident reduction compared to the risk when having achieved a traditional driving licence, and Page found a 30\% longer distance driven between the accidents, but it is unclear how these results from the French programme are measured.

In Austria, a step-by-step driving licence was implemented in two steps in 1999 and in 2003. The first is a learning step where the novice driver starts at 17 years old. The programme consists of 26 hours of theory and 12 hours of practice and then private driving practice can start. It is required in the private driving practice that the person drives at least $3,000 \mathrm{~km}$ with an experienced driver and receives accompanying education in driving school. Then the driving licence can be acquired at 18 years old. The effect of the first phase was a 15\% accident reduction for 18-19-year-olds. The second phase, implemented in 2003 , is an additional programme after the acquisition of the driving licence which the person must go through during the first year. It consists of feedback driving lessons with a driving instructor, test track training and psychological group discussions. The effect of the second phase was an approximate $30 \%$ reduction in accident involvement during the first three years, a $34 \%$ reduction in single accidents as well as a significant reduced risk for beginners including young male drivers in particular. It is not stated how these safety effects are found (Machata, 2011).

\section{NON-EUROPEAN EXPERIENCES WITH STEP-BY-STEP DRIVING LICENCES}

Description and results about step-by-step driving licences overseas are concentrated on the English-speaking industrialised countries. As they cover a large number of different regulations in federal states and nations, generalisations are made where meaningful.

In the United States, 37 states have implemented a three-step driving licence, and all states have implemented one or more elements of a step-by-step driving licence (Insurance Institute for Highway Safety 2015; Shope \& Molnar, 2003). However, only states 
with a three-step driving licence and where the effect studies are available are included: Florida, Michigan, North Carolina, California, Ohio, and Pennsylvania (Shope \& Molnar, 2003).

The step-by-step licence can start from the age of 14.75 to 16 years old. It starts with a beginner's step in which the young person must drive with a companion. In five of the six states, the young driver must drive with an experienced driver for at least 50 hours of which 10 hours must be done during the night in four of the states. This step lasts for six months in four states and 12 months in the others. Before the second step can be initiated, the novice driver must be 16 years old, with the exception of Pennsylvania where the limit is 16.5 years old. In the second step, the young person may do solo driving with restrictions such as prohibition against night driving and limitations to driving with young passengers. The night restrictions apply to all states but with a varying start and stop time.

The restriction with young passengers only applies in North Carolina and California. In North Carolina, the young person may only drive with one passenger unless they are family members. California has demands for driving with an experienced companion for the first six months if there are passengers under the age of 20 years old. After this, the next six months will only require driving with a companion of at least 25 years old when driving with young passengers at night. The second step lasts for six to 12 months. After the second step, the young person can get a valid driving licence.

The effects of the six states' step-by-step driving licence are a reduction in the various types of accidents with varying ages and at various hours of the day. The safety effects were measured in a number of different ways. All schemes resulted in safety improvements, and the reduction in the number of accidents varied between $9 \%$ and $25 \%$. A different effect due to duration of the steps was not reported. In addition, in Florida, the effect on fatalities decreased by age as the reduction was greatest among 15 -year-olds with $19 \%$ and was $11 \%$ for 16 -year-olds and $7 \%$ for 17-year-olds (Shope \& Molnar, 2003). McCartt et al. (2009) reported an almost identical tendency.

Since 1994, all of Canada, except for the Nunavut Territory, has had several versions of a step-by-step driving licence. There are differences in the implementation in the various parts of Canada. The most important initiatives are listed here. Eight out of ten provinces and two territories have two steps in their step-by-step driving licence: a beginner step and an intermediate step (Mayhew et al., 2005). The age of the person who can start taking their driving licence is 14 years old in Alberta and 16 years old in the other provinces. Before the young person can begin with the first step, it is required that they pass a theory test and that they have their parents' consent if they are under 18 or 19 years old. In the first step, the young driver must be accompanied by an experienced driver when driving. In some areas, the experienced driver must be of a certain age and have had his/her driving licence for a certain number of years. In the Yukon, there are demands of 50 hours of driving with an experienced driver while there are no similar demands in other areas. In the first step, the young person must also complete driving courses and interviews in eight of the ten provinces for the purpose of improving their driving skills. In that step, there are three restrictions that apply for more than two provinces or territories: prohibition on driving with a blood alcohol content (BAC) above zero, prohibition on night driving and passenger limitations relative to the number of seat belts, only the companion or the companion and family members. Additionally, Ontario prohibits driving on certain motorways. In two provinces and one territory, beginners must have a visible $L$ sign on the car when driving during this step. The first step lasts from six to 12 months. The duration can be reduced if they take a driving course. In four provinces, the minimum age ranges from 16 to 16.75 years old in British Columbia before the step can be completed (Mayhew et al., 2001).

Before the novice drivers can continue on to the second step, they must pass a practice test. In that step, the young person may drive alone, but with restrictions. These restrictions (applicable in more than two provinces or territories) are as follows: prohibition on driving with a BAC above zero, prohibition on night driving, passenger limitation relative to the number of seat belts, only a certain number of passengers of a certain age or a certain number of passengers at certain times. In some areas, the passenger limitations can be avoided if an experienced companion is in the car. In this step, in British Columbia the young people must have a visible New Driver sign ( $\mathrm{N}$ sign) on the car when driving. In eight provinces, the young person must also complete courses in defensive driving and interviews that should improve their driving skills. The second step lasts $12-24$ months and is completed with a practice test in three provinces and a theory test in Nova Scotia. In the other areas, there is no concluding test (Mayhew et al., 2001). 
In Ontario, the step-by-step driving licence meant a $31 \%$ reduction in the number of accidents per new driver from 1993-1995. The prohibition on driving with alcohol in one's blood resulted in a $27 \%$ reduction, and the night prohibition gave a $62 \%$ accident reduction. Also, the limitation on driving on motorway resulted in a $61 \%$ reduction in accidents (Mayhew et al., 2001). Nova Scotia saw a $24 \%$ reduction in the accident numbers among 16-year-olds. The number of accidents involving a new driver dropped with 19\% from 1993-1996. Subsequent evaluations confirmed the effect, and it turned out that the accident reduction is greatest in the first step (Mayhew et al., 2001). In 1997, Quebec implemented a step-by-step licence. The effects of their step-by-step driving licence were a 5\% drop in traffic casualties and $14 \%$ in injuries (Bouchard et al., 2000). British Columbia implemented their step-by-step driving licence in 1998. The effect hereof was a $16-17 \%$ reduction in the total number of accidents. The investigation of the effects of the restrictions did not show any difference except for the alcohol prohibition which gave a larger number of accidents (Wiggins, 2004).

All of Australia has implemented step-by-step driving licence with two steps: a beginner and an intermediate. In Western Australia, the beginner step is divided in two parts, and in New South Wales the intermediate step is further divided in two parts (Mayhew et al., 2005, New South Wales Transport, 2014). The first step can be initiated from the age of 15.75 years old in Australia Capital Territory to 16.5 in Queensland. Before the first step, the driver must pass a theory test in five states and both territories. In the first step, the driver must drive with an experienced driver and four states have a minimum requirement to the number of hours with this experienced driver. It ranges from 50 hours in New South Wales and Tasmania to 120 hours in Victoria (Mayhew et al., 2001, New South Wales Transport, 2014).

Besides driving with an experienced driver, there are three restrictions in the first step. There is a prohibition on driving with an BAC above $0.02 \%$ in three states and zero in the other areas, a speed limit in four states and one territory and a prohibition on driving with a trailer in four states. Furthermore, Western Australia has a prohibition on driving on motorways. In five states and both territories, the young driver must drive with a Learner Sign (L sign) on the car during the first step. The minimum duration of the first step ranges from six months in three states and both territories to 12 months in two states. The sec- ond step can be initiated when they are 16.5 years old in the Northern Territory and South Australia and up to 18 years old in Victoria. Before the second step, five states and both territories require the young drivers to pass a practice test while a theory test and a test in the perception of danger must be passed in one state. In this step, the young driver may drive solo with restrictions, which are prohibition on driving with a BAC equal to step 1 , speed limitation applicable in four states and one territory, prohibition on driving with a trailer applicable in three states, night restrictions in Western Australia and passenger limitation in Victoria. In five states and both territories, the novice driver must drive with a Probationary Sign ( $\mathrm{P}$ sign) on the car. Minimum duration of this second step ranges from two year in the Northern Territory to four years in Victoria (Mayhew et al., 2001, New South Wales Transport, 2014).

There have been effect studies of the step-by-step driving licence in Victoria and Queensland as well as the prohibition on night driving in Western Australia. These three effect studies all showed a reduction in the number of accidents involving young drivers. Victoria and Queensland introduced a change to the step-by-step driving licence in 1997. In Victoria, this resulted in a reduction on the accident risk and number of severe accidents for 18 to 20 -year-olds of $23 \%$ and $31 \%$, respectively during the first year after the acquisition of the driving licence. Also, the studies show a drop in the accident risk and severe accidents of $57 \%$ and $58 \%$ respectively in driving with more than one passenger during the first year after acquisition of driving licence. In Queensland, it resulted in a $30 \%$ accident reduction for new drivers. In addition, it resulted in $13 \%$ fewer fatal accidents and severe personal injuries as well as a $4 \%$ reduction on the total number of accidents. Western Australia also introduced night restrictions on driving in 2008. That resulted in a 58\% reduction in the number of personal injury accidents involving new drivers at the ages 17 to 19 years old. For those from 20 years old or older where most have a valid driving licence, there was no change (New South Wales Transport, 2014).

In New Zealand, a three-step driving licence was introduced in 1987, which applied for all new drivers at 15-24 years old. The first step is a written and oral theory test. In this step, the young person must always drive with an experienced driver of at least 20 years old who has had a driving licence for at least two years. The young person must also always have a BAC below $0.03 \%$. The first step lasts six months, 
but it can be reduced to three months by completing a driving course. The second step has restrictions and in order to get to this step the novice driver must pass a driving test. There are night restrictions and no passengers under 20 years old are allowed. The restrictions can be deviated from if an experienced driver is present. The second step lasts 18 months, but it can be reduced to half by completing a defensive or advanced driving course. The difference between a defensive and advanced driving course is that an advanced driving course is on a higher level and, as such, more difficult. After the second step, the person acquires a valid driving licence. In 1999, it was decided that the step-by-step driving licence should be mandatory to all persons and not just the 15-24-year-olds. In addition, the existing steps were modified and the age limit for the companion was removed. The changes in the first step are that there is no longer a reduction in duration and that an $\mathrm{L}$ sign must be visible on the car. In the second step, the duration is changed from 18 to 12 months for 15-24-years-olds and six months for those over 24 years old. In this step, it is possible for the 15-24-year-olds to reduce the 18 months to 12 months if they complete a defensive driving course. For drivers over 24 years old, the six months can be reduced to three months by completing an advanced driving course. In order to acquire a valid driving licence after the second step, a new driving test must be passed whereas previously it was only necessary to complete the second step. From 1987 to 1999, the number of severe accidents involving young people from the ages 15 to 24 years old was nearly halved, which is presumed to be due to the night restrictions and prohibition against driving with peers. The change in 1999 also included initiatives concerning other driving licence types. As such, it is impossible to isolate the effect of the changes in the step-by-step driving licence. The additional changes are, for instance, implementation of more severe penalties for drunk driving (Begg \& Stephenson 2003, Cieca, 2007).

\section{THE DANISH THREE-YEAR TEST SCHEME}

In Denmark, it was decided to implement a three-year trial period allowing 17 -year-olds to start driving and to drive under supervision until their 18th birthday. The driving license education can be initiated three months before the 17 th birthday. The trial period was initiated January $1^{\text {st }}, 2017$.
The driving license education remains unchanged during the trial period, but the 17-year-olds are getting a provisional driving license until their next birthday. The provisional driving license allows 17-year-olds to drive, but under constant supervision until they become 18. There are neither limitations nor requirements regarding where and when the driving is carried out as there are either a minimum requirement regarding the distance driven or mandatory road types, which have to been used by the 17-years-old drivers.

The experienced driver has to be at least 30 years old, having a driving license to passenger car issued in Denmark and have had the driving license for a minimum of 10 years without suspensions. Any sentenced fines or demerit points are not affecting this validity of the experienced driver. It is also required that the experienced driver at all time while driving with the novice driver is placed in the passenger seat and is capable in driving the car legally by him/herself. It is the young driver who is responsible for all traffic violations. However, the experienced driver can be fined in case of incapability of driving or suspension of the driving license without informing the young novice driver about it.

\section{SUMMERY AND EXPECTED EFFECT FOR THE DANISH REGULATION}

A step-by-step driving licence programme entails acquiring a driving licence in steps. The number of steps in the programme differs for the individual countries. For most investigated programmes, step 1 is related some kind of theoretical and practical tests while step 2 is related to driving together with an experienced driver, with different requirements regarding duration, minimum driven distance and any additional tests. Step 3 is related to different restrictions regarding time of day and road types, limitations of passenger volumes and any extra strict requirements regarding BAC level. In all the investigated countries, besides New Zealand, young people have freedom of choice of acquiring a driving licence in the traditional manner or through a step-by-step model although they, in some cases, will experience a significant delay of being a legal driver if only traditional driving licence is obtained.

This summary on safety effects is mainly based on the found European results. It is because the traditions with regards to age and required education 
are more identical with the Danish regulations and traditions than the non-european ones. Based on the found results it is unambiguous that implementation of step-by-step driving licence for young novice drivers improves traffic safety. With the exception of the French results, which are uncertain, but positive, all other references pointed out a positive safety effect. Some references do not clarify if they take into account the general traffic safety improvements in the form of comparison groups etc. but those which do show positive effects as well.

Where reported, there is a decreasing effect by age-the older when the driving licence is obtained, the smaller effect on safety. In Sweden, a 40\% reduction in accident risk was found when starting at 16 years old and $24 \%$ for those starting at 17.5 years old (full licence at 18). Likewise, in Florida, the reduction of the fatality rate decreased by age: 15 -year-olds with $19 \%, 11 \%$ for 16 -year-olds and $7 \%$ for 17 -year-olds. In the latter, it is, however, unclear if the effect can be associated with step 1 or step 2.

There are indications that the duration of the step with an experienced driver (step 2) increases the positive safety effects - the longer duration, the better effect. In Sweden, a 2 and a 0.5 years' step 1 reduced accident risk with 40 and $24 \%$, respectively, but it is uncertain which share is from the age effect and which share is caused by the duration. In Germany, they had 19\% lower accident risk, and they cowered involved the 17-18 years old. The similar for the 17-18 years old in Austria resulted in 15\% reduced accident risk. The non-European results cower schemes with a 6-12 months' step 2, and they reported different levels of safety effects with the lowest of $7 \%$.

In addition, most non-European studies indicate that driving without an experienced driver but with restrictions (step 3) has a better safety effect - probably also affected from a longer duration of this period in most cases. However, effects of $50-61 \%$ reductions in the number of injury accidents have been reported in results found regarding night restrictions and prohibition against driving with peers.

As the Danish trial includes only a new 'step 2', i.e. driving with an experienced driver from 17 to 18 years old, it points towards a safety effect of 15-24\% among the drivers in focus cf. the European results.

One should also mention that the general improvement of traffic safety until recently entails that, all things being equal, it will become more difficult to further improve the traffic safety. Therefore, it is reasonable that the effect on the Danish situation is in the low end - 10 to $15 \%$.

\section{REFERENCES}

Begg, D., \& Stephenson, S. (2003). Graduated driver licensing: The New Zealand experience. Journal of Safety Research, 34(1), 99-105.

Bouchard, J., Dussault, C., Simard, R., Gendreau, M., \& Lemire, A. M. (2000). The Québec Graduated Licensing System for Novice Drivers: A Two-Year Evaluation of the 1997 Reform. Highway Safety Research and Strategy. Québec, Canada.

Brems, C., \& Munch, K. (2008). Risiko i trafikken 2000-2007 (Risk in Transportation 2000-2007). DTU Transport, Copenhagen.

Cieca. (2007). Graduated Driver Licensing: Victoria, Australia and elsewhere in the English-speaking world (New Zealand, Canada and the USA) Graduated Licensing changes in Victoria, Australia.

Færdselssikkerhedskommissionen. (2013). Hver ulykke er én for meget - et falles ansvar, Fardselssikkerhedskommissionens nationale handlingsplan 2013-2020 (Each accident is one too much - a joint responsibility - The Action Plan for the Danish Traffic Safety Commission 2013-2020). Retrieved from http://www.faerdselssikkerhedskommissionen.dk/.

Gregersen, N. P., Berg, H. Y., Engström, I., Nolén, S., Nyberg, A., \& Rimmö, P. A. (2000). Sixteen years age limit for learner drivers in Sweden - an evaluation of safety effects. Accident Analysis and Prevention, 32(1), 25-35.

Harms, L. et al. (2008). A Controlled Study Of ISA-effects: Comparing Speed Attitudes Between Young Volunteers And External Controls And Effects Of Different ISA-treatments On The Speeding Of Volunteers. IET Intelligent Transport Systems, 2(2), 154-160.

Høye, A., Elvik, R., Sørensen, M. W. J., \& Vaa, T. (2012). The Handbook of Road Safety Measures. Institute of Transport Economics. Oslo.

Insurance Institute for Highway Safety. (2015). Teenagers - Driving carries extra risk for them. Retrieved from http://www.iihs. org/iihs/topics/t/teenagers/fatalityfacts/teenagers/2015.

Machata, K. (2011). Measures for young drivers in Austria. ETSC PIN Talk Budapest, KFV. Retrieved from http://archive. etsc.eu/documents/Klaus_Machata_KFV.pdf.

Mayhew, D., Simpson, H., Groseilliers, M. Des, \& Williams, A. (2001). Impact of the Graduated Driver Licensing Program in Nova Scotia. Traffic Injury Prevention, 2(3), 179-192.

Mayhew, D. R., Simpson, H. M., \& Singhal, D. (2005). Best practices for graduated driver licensing in Canada. The Traffic Injury Research Foundation. Ottawa, Canada.

McCartt, A., Mayhew, D., Braitman, K., Ferguson, S. \& Simpson, H. (2009). Effects of age and experience on young driver crashes: review of recent literature, Traffic Injury Prevention, 10, 209-219. 
Møller, M. (2000). Trafikal adfcerd hos unge bilister-unge sæetter ord på deres bilkørsel (driving behaviour among young drivers youngsters articulate their driving behaviour). In Proceedings of the Danish Annual Transport Conference, (pp. 569-578). Aalborg, Denmark.

Møller, M. (2004). Kørestil og kammerater (Driving stile and friends). Trafik \& Veje, 81(01), 40-41.

New South Wales Transport. (2014). Australian graduated licensing scheme, Policy Framework. NSW Centre for Road Safety, Transport for NSW, Sydney, Australia.

Regeringen. (2017). LBK nr 38 af 05/01/2017-Bekendtgørelse afferdselsloven (the Road Traffic Act).

Rigspolitiet. (2014). Lerervejledning om koreuddannelsen til kategori B. Version 9.14 (Teacher's Manual for driver education for cars). Retrieved from https://www.politi.dk/NR/ rdonlyres/AC495E89-710A-4868-9569-633DAAE3C0A5/0/ L\%C3\%A6aeervejledning_B_2014_KLAR_vers_3.pdf.

Rådet for Sikker Trafik. (2015a). Kørekort på prove (Driving Licence for test). Retrieved from https://www.sikkertrafik.dk/ Raad-og-viden/I-bil/Koerekort-og-koereproeve/Koerekort-paaproeve.aspx.

Rådet for Sikker Trafik. (2015b). Unge trafikanter $i$ trafikken (Young road users in the traffic). Retrieved from http://www.sikkertrafik.dk/Raad-og-viden/I-bil/Unge-trafikanter.aspx.

Schade, F.-D., \& Heinzmann, H.-J. (2013). Summative evaluation of accompanied driving from age 17. Berichte Der Bundesanstalt Fuer Strassenwesen. Unterreihe Mensch Und Sicherheit. Retrieved from http://bast.opus.hbz-nrw.de/volltexte/2013/621/pdf/M218b_en.pdf.

Shope, J. T., \& Molnar, L. J. (2003). Graduated driver licensing in the United States: evaluation results from the early programs. Journal of safety research. Association for the Advancement of Automotive Medicine, 47, 536-538.

Sølund, J. (2014). Høringssvar - Privat øvelseskørsel 17 årige. Notat til Justitsministeriet (Statement - Private driving training for 17-years-old - Note to The Ministry of Justice). The Danish Traffic Safety Council. Copenhagen.

Statistics Denmark (2016). Tilskadekomne og drcebte i fardselsuheld efter område, personskade, indblandede transportmidler, alder og køn (Injured and killed in traffic accidents after area, personal injury, involved road users, age and gender). Retrieved from http://www.statistikbanken.dk/statbank5a/default. asp? $\mathrm{w}=2560$.

Wiggins, S. (2004). Graduated Licensing Program Interim Evaluation Report - Year 3. pp. 1-182. Insurance Corporation of British Columbia. Victoria, British Columbia, Canada. 